\title{
Spontaneous splenic rupture mimicking pneumonia: a case report Karen A MacKenzie ${ }^{1,2}$ and Roy L Soiza*1,2
}

\author{
Address: ${ }^{1}$ Department of Medicine for the Elderly, Woodend Hospital, Aberdeen, AB15 6XS, UK and ${ }^{2}$ Division of Applied Medicine, University of \\ Aberdeen, Polwarth Building, Foresterhill, Aberdeen, AB25 2ZD, UK \\ Email: Karen A MacKenzie - kamackenzie@doctors.org.uk; Roy L Soiza* - r.l.soiza@abdn.ac.uk \\ * Corresponding author
}

Published: 15 July 2008

Cases Journal 2008, I:35 doi:10.1186/1757-1626-1-35

This article is available from: http://www.casesjournal.com/content/I/I/35

(C) 2008 MacKenzie and Soiza; licensee BioMed Central Ltd.

This is an Open Access article distributed under the terms of the Creative Commons Attribution License (http://creativecommons.org/licenses/by/2.0), which permits unrestricted use, distribution, and reproduction in any medium, provided the original work is properly cited.

Received: 28 May 2008

Accepted: 15 July 2008

\begin{abstract}
A 74-year-old gentleman presented with a history of left-sided pleuritic chest and upper abdominal pain. Examination and chest $x$-ray findings were suggestive of pneumonia. An abdominal ultrasound was suggestive of spontaneous splenic rupture. An abdominal computed tomography scan showed a splenic laceration and large peri-splenic haematoma. The advice from the on-call surgical team was to treat conservatively but the patient's condition deteriorated suddenly and he died. Spontaneous splenic rupture is uncommon but probably under-diagnosed and should be considered in all patients presenting with non-specific abdominal pain. The optimal management strategy for the older patient with spontaneous ruptured spleen is unknown.
\end{abstract}

\section{Case Report}

A 74-year-old Caucasian man presented with a one-week history of gradual onset, sharp epigastric and left-sided lower chest pain. The pain radiated to his left shoulder and was exacerbated by movement and coughing. The patient denied any history of trauma, foreign travel and was not on anticoagulants. His past medical history included mild ischaemic heart disease and depression. He was an active man, still in employment, who did not smoke or drink alcohol.

On examination he was tachycardic at 110 beats per minute, normotensive and had a temperature of $37.8^{\circ} \mathrm{C}$. He was tachypnoeic with oxygen saturation of $91 \%$ on air. There was dullness to percussion and decreased air entry at the left base. Examination of the abdomen revealed mild generalised tenderness to palpation, worst in the epigastrium. There was no guarding, rebound tenderness or evidence of bruising.
Routine admission blood tests revealed a haemoglobin of $16.3 \mathrm{~g} / \mathrm{dl}$, a normal white cell count and C-reactive protein. His urea and creatinine were $19.1 \mathrm{mmol} / \mathrm{l}$ and 117 $\mu \mathrm{mol} / \mathrm{l}$ respectively. His liver function tests were deranged with a bilirubin of $61 \mu \mathrm{mol} / \mathrm{l}$, alanine aminotransferase $97 \mathrm{U} / \mathrm{l}$, alkaline phosphatase $436 \mathrm{U} / \mathrm{l}$ and gamma glutamic transpeptidase $398 \mathrm{U} / \mathrm{l}$. A chronic liver disease screen was normal, and there was no serological evidence of viral infection (including hepatitis and Epstein Barr virus).

Chest x-ray showed a left pleural effusion and consolidation. He was initially treated for pneumonia.

Chest and abdominal ultrasound scans showed a large amount of free fluid surrounding the spleen suggesting splenic rupture and a moderate left sided pleural effusion. The spleen was otherwise normal in size and appearance, and no other intra-abdominal abnormality was found. 
He was referred to the surgeons who felt that the most appropriate line of management was conservative and suggested a follow-up ultrasound scan in four months time to monitor progress. Draining the pleural effusion was thought to be too risky due to its proximity to the haematoma.

During the subsequent week the patient developed pleuritic chest pain and a CT pulmonary angiogram and upper abdominal CT scan were performed. These showed no evidence of pulmonary embolism but revealed a splenic laceration with a peri-splenic subcapsular haematoma, measuring $16 \times 14 \mathrm{~cm}$ in axial dimension (Figure 1), with a reactive pleural effusion. Once again, there was no other abnormality seen in the liver or spleen.

Unfortunately, before the patient could be re-reviewed regarding surgical intervention, he had an unwitnessed cardiac arrest and died. The family declined a post-mortem examination.

\section{Discussion}

Rupture of the spleen is most commonly seen soon after blunt trauma to the abdomen or lower ribs. Iatrogenic splenic injuries are thought to be responsible for up to $40 \%$ of all splenectomies performed [1].

Spontaneous splenic rupture is uncommon but probably under-diagnosed in the absence of trauma [2]. Such

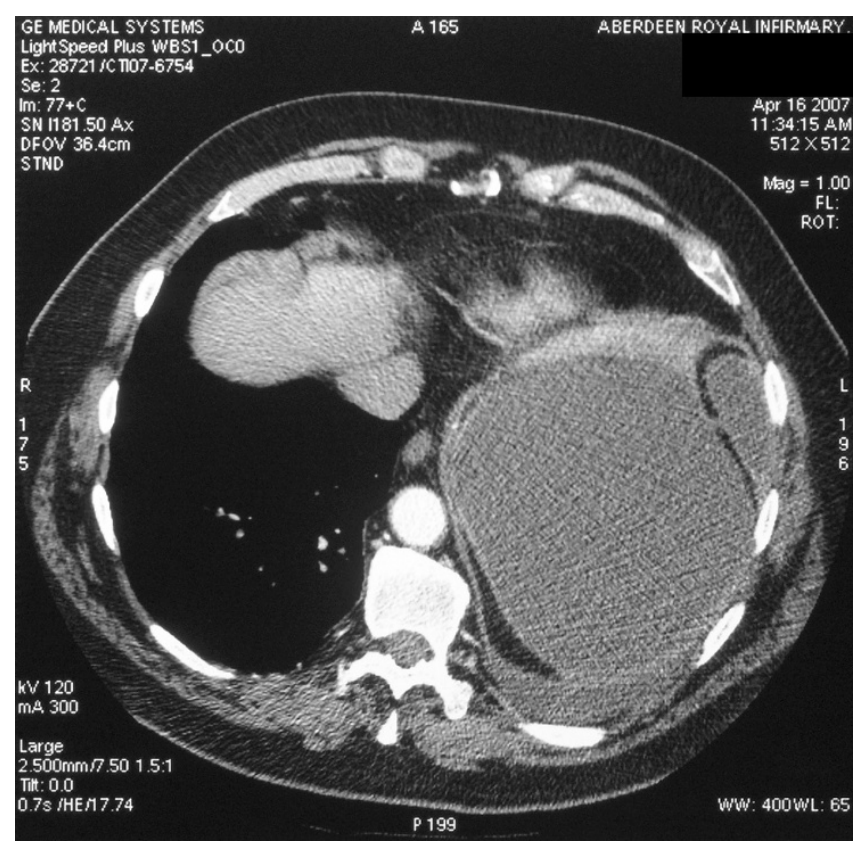

Figure I

Computed tomography scan. Axial view of patient's CT scan showing a large peri-splenic haematoma. splenic rupture may be classified as either "pathological" in the presence of underlying disease or "spontaneous" if normal $[2,3]$. There is debate as to whether this entity exists or whether rupture always occurs in the presence of undiagnosed disease.

Classically patients may present with symptoms of pain, tenderness and guarding of the left upper quadrant and hypovolaemic shock [4]. Left-shoulder tip pain, particularly when lying flat (Kehr's sign), is caused by blood irritating the left hemi-diaphragm and is said to be present in $50 \%$ of cases of splenic rupture [5]. However, symptoms can be subtle and the condition may be mistaken for angina pectoris, myocardial infarction, pulmonary embolism, peptic ulceration or, as in this case, pneumonia.

The management of spontaneous and traumatic splenic rupture is similar. In stable patients there is a relatively recent trend towards non-operative management often due to concerns regarding the risk of post-splenectomy infection [6,7]. A search of Medline, Embase and all Evidence Based Medicine Reviews combining several search terms for older people and spleen or splenic rupture failed to come up with any relevant articles to guide management. Similarly, a search for published guidelines on NHS Scotland e-library search facility did not reveal any specific guidelines for the management of spontaneous splenic rupture. The Society for Surgery of the Alimentary Tract recommend non-operative support with in-hospital observation for up to 5 days is adults with splenic injury and haemodynamic stability. Accepted indications for splenectomy in adults include haemodynamic instability, bleeding greater than $1000 \mathrm{ml}$, transfusion of more than 2 units of blood, or other evidence of ongoing blood loss [8]. However, these guidelines are chiefly based on traumatic splenic rupture in younger people. Since older people are known to have altered homeostatic mechanisms that make them more prone to haemodynamic collapse [9], it is unclear if more aggressive intervention may be warranted. Furthermore, concerns about rendering patients asplenic for decades are important only in younger patients. Our literature search revealed very few comparable cases to ours, though Athey and colleagues [10] report a case in an older patient treated with splenectomy who died soon after the operation. Therefore, both the incidence and best management of this condition in older people remain unknown.

This case highlights that spontaneous splenic rupture can occur in a previously well, haemodynamically stable patient with no obvious cause and should be suspected in patients with non-specific abdominal pain. In the case of our patient, this was only diagnosed during investigation for deranged liver function tests for which no clear cause was found. There is little evidence in the literature to guide 
the management of spontaneous splenic rupture in older people.

\section{Consent}

Written informed consent was obtained from the patient's next of kin for publication of this case report and accompanying images. A copy of the written consent is available for review by the Editor-in-Chief of this journal.

\section{Competing interests}

The authors declare that they have no competing interests.

\section{Authors' contributions}

KAM wrote the case report and accompanying discussion. RLS revised the original manuscript and produced the final draft.

\section{References}

I. Cassar K, Munro A: Clinical Review. latrogenic splenic injury. J $R$ Coll Surg Edinb 2002, 47:73I-74I.

2. Debnath $D$, Valerio $D$ : Atraumatic rupture of the spleen in adults. I $R$ Coll Surg Edinb 2002, 47:437-445.

3. Sterlacci W, Heiss S, Augustin F, Tzankov A: Splenic rupture, beyond and behind: a histological, morphological and followup study of 254 cases. Pathobiology 2006, 73:280-87.

4. Swirsky D: The spleen and its disorders. In Oxford Textbook of Medicine 4th edition. Edited by: Warrell DA, Cox TM, Firth JD. Oxford University Press; 2004:3609-3616.

5. Eowenfels $A B$ : Kehr's sign: a neglected aid in rupture of the spleen. N Engl J Med 1966, 274:10 I 9.

6. Guth AA, Pachter HL, Jacobowitz GR: Rupture of the pathologic spleen: is there a role for nonoperative therapy? J Trauma |996, 41:214-218.

7. Pachter HL, Guth AA, Hofstetter SR, Spencer FC: Changing patterns in the management of splenic trauma: the impact of nonoperative management. Ann Surg 1998, 227:708-719.

8. Society for Surgery of the Alimentary Tract: Surgical treatment of disease and injury of the spleen. [http://www.ssat.com/cgi-bin/ diseasesInjuriesSpleen.cgi]. accessed 28th February 2008.

9. Young A: Ageing and physiological function. Philos Trans $R$ Soc Lond B Biol Sci 1997, 352:1837-1843.

10. Athey RJ, Barton LL, Horgan LF, Wood BH: Spontaneous splenic rupture in a patient with pneumonia and sepsis. Acute Medicine 2006, 5:21-23.
Publish with Bio Med Central and every scientist can read your work free of charge

"BioMed Central will be the most significant development for disseminating the results of biomedical research in our lifetime. "

Sir Paul Nurse, Cancer Research UK

Your research papers will be:

- available free of charge to the entire biomedical community

- peer reviewed and published immediately upon acceptance

- cited in PubMed and archived on PubMed Central

- yours - you keep the copyright

Submit your manuscript here:

http://www.biomedcentral.com/info/publishing_adv.asp
BioMedcentral 